\title{
The Role of Industry Effect and Market States in Taiwanese Momentum
}

\author{
Hsiao-Peng $\mathrm{Fu}^{1}$ \\ ${ }^{1}$ Department of Finance, Providence University, Taiwan, R.O.C. \\ Correspondence: Hsiao-Peng Fu, Department of Finance, Providence University, 200, Section 7, Taiwan Boulevard \\ Road, Shalu District, Taichung 43301, Taiwan, R.O.C. Tel: 8864-2632-8001 Ext. 13614.
}

Received: March 1, 2016

Accepted: March 9, 2016

Online Published: April 6, 2016

doi:10.5430/ijfr.v7n2p183

URL: http://dx.doi.org/10.5430/ijfr.v7n2p183

\begin{abstract}
A prior research detects significant seasonal Taiwanese momentum. In this follow-up analysis, I report the seasonal momentum can neither be interpreted by the industy effect suggested by Moskowitz and Grinblatt (1999), nor the market state effect proxy for either overreaction suggested by Daniel et al. (1998) or gradual dessenmination of informationby by Hong and Stein (1999). Note, however, that the industry effect does explain about $40 \%$ of the profitability of the Taiwaneses momentum.
\end{abstract}

Keywords: price momentum, seasonality, emerging markets

\section{Introduction}

Since the pioneering work of Jegadeesh and Titman (1993), price momentum has been the interest of enormous studies. In general, most research agrees on the existence of momentum, however, by contrast, no consistent agreement has been reached for the underlying rationales. Among others, the notable behavioral models intending to explain price momentum including the overconfidence and self-attribution induced overreaction model developed by Daniel, Hirshleifer and Subrahmanyam (1998, henceforth as DHS) and the gradual-information-diffusion model proposed by Hong and Stein (1999, henceforth as HS). DHS suggest that investors are facing overconfidence bias and as more information is in favour of their previous prediction, self-attribution bias makes investors become even more overconfident and hold more positions. Consequently, they assert that bullish markets tend to attract more momentum trading than bearish markets and thereby are followed by higher momentum profits. On the other hand, HS predict that momentum traders are stimulated to buy more securities in the presence of price continuation, resulting in buying forces that push prices further up. In sum, both models profile up markets leading higher momentum profits than down markets (Cooper et al., 2004). As a result, Cooper et al. (2004) propose and empiricaly find momentum effects only arise in up markets, not in down markets.

In addition, among other rationales, Moskowitz and Grinblatt (1999) report dissipation of momentum profits after controlling for an industry effect. Conversely, Grundy and Martin (2001) discover persistence of momentum returns even conditioned on the industry effect. Jegadeesh and Titman (2002) point out that the key difference of the methodology between the two studies is Moskowitz and Grinblatt do not skip one month between formation and post-formation periods, while Grundy and Martin does.

Turning to momentum in Taiwan, early research normally do not detect momentum in Taiwan nor in most Asian markets (e.g., Rouwenhorst, 1999; Hameed and Yuanto, 2002; Chui et al., 2003; Griffin et al., 2005). Recently, however, Fu and Wood (2010) report that seasonality is the reason for the lack of momentum throughtout whole years in Taiwan. That is, momentum is evident in April to Auguest but is weak in other calendar months. Providing further evidence of their research, this paper investigates the explanatory power of the industry effect and market states, respectively, for the April-Auguest momentum.

Partially confirming the hypothesis of Moskowitz and Grinblatt's (1999), evidence of this paper showing approximately $40 \%$ of momentum profitability can be explained by the industry effect, whereas the remaining $60 \%$ is intact. In addition, market states show only weak explanatory capacity for the Taiwanese momentum. In brief, DHS and HS's assertion seems do not find support in this analysis.

This research contributes to the momentum literature by providing out-of-sample tests for rationales of momentum. Not surprisingly, the ratinales for momentum in the US stock markets seem not be the exact reasons for the Taiwanses momentum. Hence, existence of momentum is seemingly a global phenomenon, driving forces by contrast 
are more likely market specific.

The rest of this paper is structured as follows. The following section discusses data and methodology. Section 3 and 4 documents empirical results and concluding remarks, respectively.

\section{Data and Methodology}

I use the exact same sample as used by Fu and Wood (2010). That is, from Taiwan Economic Journal (TEJ) dataset, I obtain monthly data from July 1975 to December 2003. All non-financial common stocks listed on the Taiwan Stock Exchange (TWSE) are included. Specifically, I use two data sets from TEJ. The first data base contains historical records for stocks listed on the TWSE at the end of December 2003, while the second one is composed of data for securities that have been listed on the exchange sometime during the sample period of July 1975-December 2003 but dropped out of the exchange before the end of December 2003. Accordingly, there are 657 shares in total and 47 to 498 stocks in various rank and post-rank periods.

Stocks whose market prices are below one New Taiwan Dollars at the end of the ranking periods are discarded over corresponding ranking periods so as to eliminate potential bias from microstructure issues (e.g., bid-ask bounces) inherited from extreme low price securities (Jegadeesh and Titman, 2001). Furthermore, to reduce survivorship bias, I include as many qualifying stock as is reasonably possible to avoid focusing solely on well-established healthy firms. Therefore, our sample includes stocks which, during holding periods, de-list from the TWSE or downgrade to in-advance-full-delivery stocks. To avoid potential short-term bid-ask swing effects, I use a one-month lag between the ranking periods and the holding periods.

As in Jegadeesh and Titman (1993), I use over-lapping holding periods to increase the number of replications and thereby avoid small sample problems. Like Rouwenhorst (1999), after dropping out ten percent outliners (five percent for top and bottom respectively) of ranking period returns, securities are grouped into three portfolios based on the previous six month returns: the bottom $30 \%$ stocks with the worst performance constitute the loser portfolios (or "L"), the $40 \%$ stocks with the middle performance are in the middle portfolios (or "M"), and the top 30\% stocks with best performance form the winner portfolios (or "W"). At the end of each month, i.e., defined as portfolio formation date, I form the three portfolios described above based on past six month performance, and estimate returns for the subsequent six months.

Following the convention adopted in the momentum literature, returns for each portfolio for holding periods is estimated on the basis that all stocks are equally weighted within each portfolio, regardless of their market values (e.g., Jegadeesh and Titman, 1993). As regards the sub-period analysis, for comparability purpose, I follow Chui et al. (2003) by using May 1987 and June 1997 as two breakpoints, where May 1987 is the time when the Taiwanese stock market starts to allow foreigner ownership of listing firms, and June 1997 is the time when the Asian financial crisis occurred.

To avoid the measurement problem in Moskowitz and Grinblatt (1999), in the following tests of the industry effect in the Taiwanese stock market, I skip one month between ranking and post-ranking periods. Besides, in formation industry benchmark portfolios, a procedure similar to Lee and Swaminathan (2000) has been used. In particular, 18 industries are used to construct industry reference portfolios and industry-adjusted returns on individual stocks are estimated by subtracting corresponding industry portfolio returns from individual raw returns. The eighteen industries are (industry codes are in parenthesis): cement (11), foods (12), plastics (13), textiles (14), electricity and machinery (15), electricity appliance and cable (16), chemicals (17), glass and ceramics (18), paper and pulp (19), steel and iron (20), rubber (21), automobile (22), electronics (23), construction (25), transportation (26), tourism (27), wholesale, retail, and conglomerate $(29,98)$, and others (99).

\section{Empirical Results}

\subsection{Momentum Returns Controlling for Industy Effect}

The April-to-August results in Table 1 reveals that although industry-conditioned momentum returns decreased by a significant portion (i.e., -0.52 with $t$-stat.-3.08), still a significant momentum returns is left intact (see the last column in the second row). In particular, for the April-to-August effect, the after-adjustment momentum returns is approximately 60 percent of the before-adjustment momentum returns (or $0.72 / 1.24=58 \%$ ). In sum, the industry effect does not critically alter the significance of momentum profits, in spite of their partial explanatory power. 
Table 1. Seasonal momentum returns conditioned by industry effect

\begin{tabular}{ccccc}
\hline & $\mathrm{W}$ & $\mathrm{M}$ & $\mathrm{L}$ & $\mathrm{W}-\mathrm{L}$ \\
\hline Raw returns & 0.16 & -0.41 & -1.08 & 1.24 \\
& $(0.14)$ & $(-0.38)$ & $(-0.97)$ & $(3.91)$ \\
\hline Industry adjusted returns & 0.32 & 0.07 & -0.41 & 0.72 \\
& $(2.70)$ & $(1.18)$ & $(-3.74)$ & $(3.42)$ \\
\hline Adjusted returns minus raw returns & 0.15 & 0.48 & 0.68 & -0.52 \\
& $(0.14)$ & $(0.44)$ & $(0.61)$ & $(-3.08)$
\end{tabular}

The $t$ statistics are in parentheses.

\subsection{Subperiod Analysis of the Industry Effect}

The subperiod analysis in Tables 2 documents robustness of the momentum profitability controlling for industry effect as well as the significant role of the industry effect with the exception of a weaker role over the post-crisis period shown in Panel C.

Table 2. Subperiod analysis of seasonal momentum returns conditioned by industry effect

\begin{tabular}{ccccc}
\hline & $\mathrm{W}$ & $\mathrm{M}$ & $\mathrm{L}$ & $\mathrm{W}-\mathrm{L}$ \\
\hline Panel A: Raw returns & & & & \\
\hline Jun. 1981 - May. 1987 & 1.27 & 0.01 & -0.28 & 1.54 \\
(the pre-liberalization period) & $(0.92)$ & $(0.01)$ & $(-0.19)$ & $(3.16)$ \\
\hline Jun. 1987 - Jun. 1997 & 0.99 & 0.91 & 0.38 & 0.62 \\
(the pre-crisis period) & $(0.48)$ & $(0.47)$ & $(0.19)$ & $(1.35)$ \\
\hline Jul. 1997 - Jun. 2003 & -2.51 & -3.33 & -4.65 & 2.13 \\
(the post-crisis period) & $(-1.80)$ & $(-2.35)$ & $(-2.79)$ & $(2.95)$ \\
\hline Panel B: Industry adjusted returns & \multicolumn{5}{c}{} \\
\hline Jun. 1981 - May. 1987 & 0.63 & -0.25 & -0.30 & 0.93 \\
(the pre-liberalization period) & $(3.72)$ & $(-2.55)$ & $(-1.46)$ & $(2.63)$ \\
\hline Jun. 1987 - Jun. 1997 & -0.04 & 0.19 & -0.22 & 0.18 \\
(the pre-crisis period) & $(-0.23)$ & $(2.03)$ & $(-1.60)$ & $(0.63)$ \\
\hline Jul. 1997 - Jun. 2003 & 0.67 & 0.16 & -0.88 & 1.55 \\
(the post-crisis period) & $(2.71)$ & $(1.58)$ & $(-3.45)$ & $(3.21)$ \\
\hline Panel C: -Decreases(+Increases), i.e., adjusted returns & minus raw returns \\
\hline Jun. 1981 - May. 1987 & -0.64 & -0.26 & -0.02 & -0.62 \\
(the pre-liberalization period) & $(-0.46)$ & $(-0.19)$ & $(-0.01)$ & $(-3.20)$ \\
\hline Jun. 1987 - Jun. 1997 & -1.03 & -0.72 & -0.59 & -0.44 \\
(the pre-crisis period) & $(-0.51)$ & $(-0.36)$ & $(-0.30)$ & $(-1.71)$ \\
\hline Jul. 1997 - Jun. 2003 & 3.18 & 3.49 & 3.77 & -0.58 \\
(the post-crisis period) & $(2.20)$ & $(2.37)$ & $(2.51)$ & $(-1.42)$ \\
\hline
\end{tabular}

The $t$ statistics are in parentheses. 


\subsection{Momentum Returns Conditional on Market States}

As in Cooper, Gutierrez and Hameed (2004), I respectively use 12 and 36 month lagged market returns to define the up and down markets since some length of time period is needed to encourage delayed overreaction in the two behavioural theories. Specifically, for each holding month, market state is categorized as up when previous 12 (or 36) month market returns are above or equal zero. Otherwise, it is regarded as down. With respect to measures of momentum returns, besides the normal raw returns, I also compute respective abnormal returns on CAPM and Fama-French 3-factor model. As for tests of equality of raw or abnormal returns across up and down markets, we follow Cooper, Gutierrez and Hameed, regressing momentum returns on an intercept and an up dummy as the equation below:

$$
R_{p k}=a_{p}+b_{p} D_{k}+e_{p k}
$$

Where $\mathrm{R}_{\mathrm{pk}}$ denotes raw returns or abnormal returns in CAPM or Fama-French (1993) three-factor model for portfolio $p$ in holding month $k$ that exclusively belongs to the period between April and August, $\alpha_{p}$ is the intercept for portfolio $p$, and $b_{p}$ is the coefficient for dummy variable $D_{k}$, which is one in up markets, and zero in down markets.

Table 3. Seasonal momentum returns conditioned by market states

\begin{tabular}{lcccccc}
\hline & \multicolumn{2}{c}{ Up Markets } & \multicolumn{2}{c}{ Down Markets } & \multicolumn{2}{c}{ Up - Down (i.e., $\left.b_{p}\right)$} \\
\hline & 12-mth lag & 36-mth lag & 12-mth lag & 36-mth lag & 12-mth lag & 36-mth lag \\
\hline Raw return & 1.49 & 1.61 & 1.18 & 0.77 & 0.31 & 0.84 \\
& $(3.38)$ & $(3.98)$ & $(2.28)$ & $(1.30)$ & $(0.46)$ & $(1.15)$ \\
\hline CAPM alpha & 1.21 & 1.49 & 1.54 & 0.32 & -0.33 & 1.17 \\
& $(2.92)$ & $(3.79)$ & $(2.52)$ & $(0.41)$ & $(-0.50)$ & $(1.66)$ \\
\hline Fama-French alpha & 0.86 & 1.08 & 1.81 & 0.95 & -0.95 & 0.13 \\
& $(1.80)$ & $(2.60)$ & $(2.81)$ & $(1.35)$ & $(-1.47)$ & $(0.21)$
\end{tabular}

The $t$ statistics are in parentheses.

Like findings in the U.S. market revealed by Cooper, Gutierrez and Hameed, evidence in Table 3 shows generally large and significant momentum returns on up markets. Specifically, the raw momentum returns in up markets defined by 12 -month and 36-month lagged market returns are 1.49 percent $(\mathrm{t}=3.38)$ and 1.61 percent $(\mathrm{t}=3.98)$ per month respectively. The abnormal returns in CAPM or Fama-French model also exhibit significant results. Conversely, unlike the negative returns in down markets in the U.S., the corresponding momentum returns are generally significant positive when the market states are determined by the 12-month lagged market returns. Consequently, the momentum return differential between the up and down market states is only at best weak positive, while that in the U.S. are strong positive. In other words, we do not find strong evidence supportive the assertion of DHS and HS that momentum effects are stronger subsequent to up markets.

\subsection{Subperiod Analysis of the Market State Effect}

Subperiod analysis reported in Table 4 is generally identical to that in Table 3. 
Table 4. Subperiod analysis of seasonal momentum returns conditioned by market states

\begin{tabular}{|c|c|c|c|c|c|c|}
\hline & \multicolumn{2}{|c|}{ Up Markets } & \multicolumn{2}{|c|}{ Down Markets } & \multicolumn{2}{|c|}{ Up - Down (i.e., $b_{p}$ ) } \\
\hline & 12-mth lag & 36-mth lag & 12-mth lag & 36-mth lag & 12-mth lag & 36-mth lag \\
\hline \multicolumn{7}{|c|}{ Panel A: July 1981 - May 1987 (the pre-liberlisation period) } \\
\hline \multirow[t]{2}{*}{ Raw return } & 1.59 & 1.79 & 1.25 & 0.42 & 0.33 & 1.38 \\
\hline & $(2.26)$ & $(2.69)$ & (1.41) & $(0.56)$ & $(0.29)$ & (1.09) \\
\hline \multirow[t]{2}{*}{ CAPM alpha } & 1.33 & 1.75 & 0.06 & 0.71 & 1.27 & 1.04 \\
\hline & $(1.85)$ & $(2.61)$ & $(0.04)$ & $(0.81)$ & $(1.25)$ & $(1.06)$ \\
\hline \multirow[t]{2}{*}{ Fama-French alpha } & 1.07 & 1.31 & -0.61 & -0.03 & 1.68 & 1.34 \\
\hline & $(1.08)$ & $(1.54)$ & $(-0.58)$ & $(-0.02)$ & $(2.22)$ & $(1.56)$ \\
\hline \multicolumn{7}{|c|}{ Panel B: June 1987 - June 1997 (the pre-crisis period) } \\
\hline \multirow[t]{2}{*}{ Raw return } & 1.24 & 0.92 & 0.10 & 0.41 & 1.14 & 0.50 \\
\hline & $(1.92)$ & $(1.54)$ & $(0.14)$ & $(0.48)$ & $(1.13)$ & $(0.43)$ \\
\hline \multirow[t]{2}{*}{ CAPM alpha } & 0.91 & 0.69 & 1.01 & 1.03 & -0.10 & -0.34 \\
\hline & $(1.46)$ & $(1.18)$ & $(1.68)$ & $(0.87)$ & $(-0.11)$ & $(-0.34)$ \\
\hline \multirow[t]{2}{*}{ Fama-French alpha } & 0.11 & 0.29 & 1.05 & 0.81 & -0.94 & -0.52 \\
\hline & $(0.17)$ & $(0.54)$ & $(1.63)$ & $(0.58)$ & $(-1.07)$ & $(-0.58)$ \\
\hline \multicolumn{7}{|c|}{ Panel C: July 1997 - June 2003 (the post-crisis period) } \\
\hline \multirow[t]{2}{*}{ Raw return } & 1.99 & 3.25 & 2.56 & 1.30 & -0.58 & 1.95 \\
\hline & $(1.76)$ & $(4.01)$ & $(2.64)$ & $(1.08)$ & $(-0.39)$ & $(1.37)$ \\
\hline \multirow[t]{2}{*}{ CAPM alpha } & 2.08 & 3.42 & 1.47 & -2.08 & 0.61 & 5.50 \\
\hline & $(2.27)$ & $(4.25)$ & $(0.96)$ & $(-1.67)$ & $(0.48)$ & $(4.48)$ \\
\hline \multirow[t]{2}{*}{ Fama-French alpha } & 1.90 & 1.96 & 1.89 & 0.97 & 0.01 & 1.00 \\
\hline & $(1.85)$ & $(2.82)$ & $(2.06)$ & $(0.89)$ & $(0.01)$ & $(1.29)$ \\
\hline
\end{tabular}

The $t$ statistics are in parentheses.

\section{Conclusions}

$\mathrm{Fu}$ and Wood (2010) detect significant seasonal Taiwanese momentum over calendar months of Aprio to Auguest. In this analysis, I report further evidence that the seasonal momentum can neither be interpreted by the industy effect suggested by Moskowitz and Grinblatt (1999), nor the market state effect proposed by Cooper et al. (2004). Note that the industry effect however does explain about $40 \%$ of the profitability of the seasonal Taiwaneses momentum. Further, as market states are proxy for either overreaction behaviors of overconfident investors suggested by Daniel et al. (1998) or trading activities of momentum traders argued by Hong and Stein (1999), the failure of explatory power of markets states implies a potential failure of the models of Daniel et al. (1998) and Hong and Stein (1999) in explaining the Taiwanese seasonal momentum. That is, trading activities from overconfidence and/or momentum chasing are not as strong in Taiwan as in the U.S. The weaker results are likely to contradict ituition that retail investors are more prone to be overconfident and/or chasing momentum strategies than institutional investors since retail investors dominate the Taiwaneses stock market while, by contrast, institutional investors dominate the U.S. stock markets.

\section{References}

Chui, A., Titman, S., \& Wei, J. (2003). Momentum, legal systems and ownership structure: an analysis of Asian stock markets. Unpublished working paper. University of Texas at Austin.

Cooper, M., Gutierrez Jr., R., \& Hameed, A. (2004). Market states and momentum. Journal of Finance, 59, 1345-1365. http://dx.doi.org/10.1111/j.1540-6261.2004.00665.x 
Daniel, K., Hirshleifer, D., \& Subrahmanyam, A. (1998). Investor psychology and security market under-and overreactions. Journal of Finance, 53(6), 1839-1886. http://dx.doi.org/10.1111/0022-1082.00077

Fama, F., \& French, K. (1993). Common risk factors in the returns on stocks and bonds. Journal of Financial Economics, 33, 3-56. http://dx.doi.org/10.1016/0304-405X(93)90023-5

Fu, Hsiao-Peng, \& Wood, A. (2010). Momentum Profits in Taiwan: Seasonality Matters! Applied Economics Letters, 17(13), 1247-1253. http://dx.doi.org/10.1080/00036840902917589

Griffin, J., Ji, X., \& Martin, S. (2005). Global momentum strategies: A portfolio perspective. Journal of Portfolio Management (winter), 23-29. http://dx.doi.org/ 10.3905/jpm.2005.470576

Grundy, B., \& Martin, J. (2001). Understanding the nature of the risks and the source of the rewards to momentum investing. Review of Financial studies, 14, 29-78. http://dx.doi.org/10.1093/rfs/14.1.29

Hameed, A., \& Yuanto, K. (2002). Momentum strategies: evidence from the pacific basin stock markets. Journal of Financial Research, 25(3), 387-397. http://dx.doi.org/10.1111/1475-6803.00025

Hong, H., \& Stein, J. C. (1999). A unified theory of underreaction, momentum trading, and overreaction in asset markets. Journal of Finance, 54, 2143-2184. http://dx.doi.org/10.1111/0022-1082.00184

Jegadeesh, N., \& Titman, S. (1993). Returns to buying winners and selling losers: implications for stock market efficiency. Journal of Finance, 48, 65-91. http://dx.doi.org/10.1111/j.1540-6261.1993.tb04702.x

Jegadeesh, N., \& Titman, S. (2001). Profitability of momentum strategies: An evaluation of alternative explanations. Journal of Finance, 56, 699-720. http://dx.doi.org/10.1111/0022-1082.00342

Jegadeesh, N., \& Titman, S. (2002). Momentum. Unpublished working paper. University of Illinois.

Lee, C., \& Swaminathan, B. (2000). Price momentum and trading volume. Journal of Finance, 55, 2017-2069. http://dx.doi.org/10.1111/0022-1082.00280

Moskowitz, T., \& Grinblatt, M. (1999). Do industries explain momentum? Journal of Finance, 54, 1249-1290. http://dx.doi.org/10.1111/0022-1082.00146

Rouwenhorst, K. (1999). Local return factors and turnover in emerging stock markets. Journal of Finance, 54, 1439-1464. http://dx.doi.org/10.1111/0022-1082.00151 